\title{
MODEL-BASED COMPUTATION OF TOTAL STRESSED BLOOD VOLUME FROM A \\ PRELOAD REDUCTION EXPERIMENT
}

\author{
A. PIRONET*, T. DESAIVE*, J.G. CHASE**, \\ P. MORIMONT*, P.C. DAUBY*
}

* GIGA-CARDIOVASCULAR SCIENCES, UNIVERSITY OF LIEGE, LIEGE, BELGIUM

** DEPARTMENT OF MECHANICAL ENGINEERING, UNIVERSITY OF CANTERBURY, CHRISTCHURCH, NEW ZEALAND 


\section{INTRODUCTION}

\section{LUMPED-PARAMETER CVS MODELS}

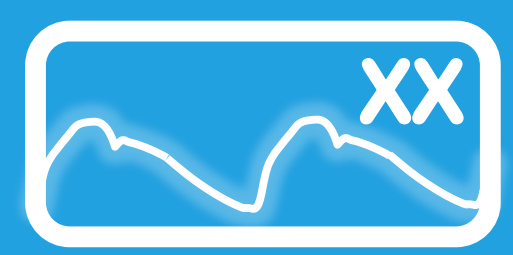

Limited amount of data in the ICU

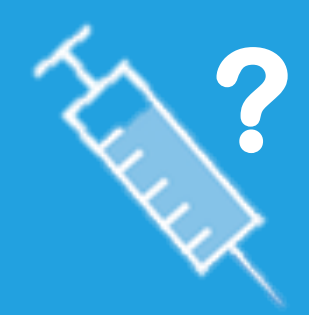

Difficult treatment

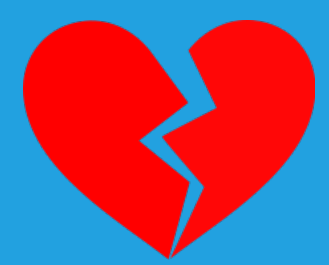

Cardiovascular diseases 


\section{INTRODUCTION}

\section{LUMPED-PARAMETER CVS MODELS}

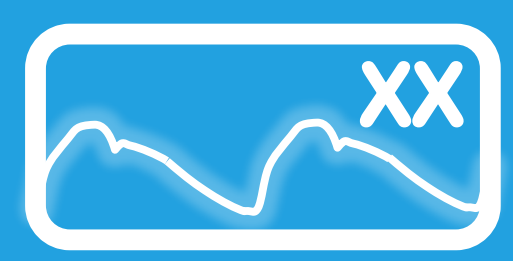

Limited amount of data in the ICU

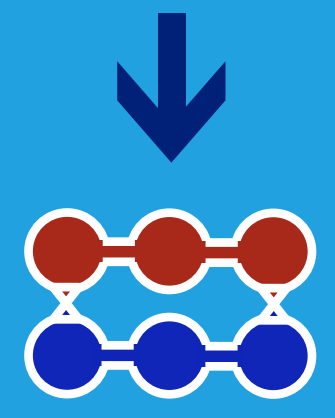

Mathematical model

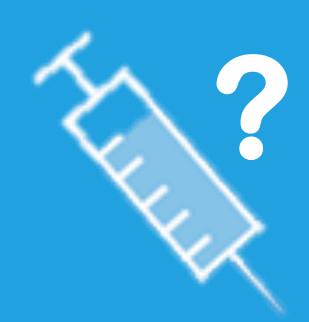

Difficult treatment

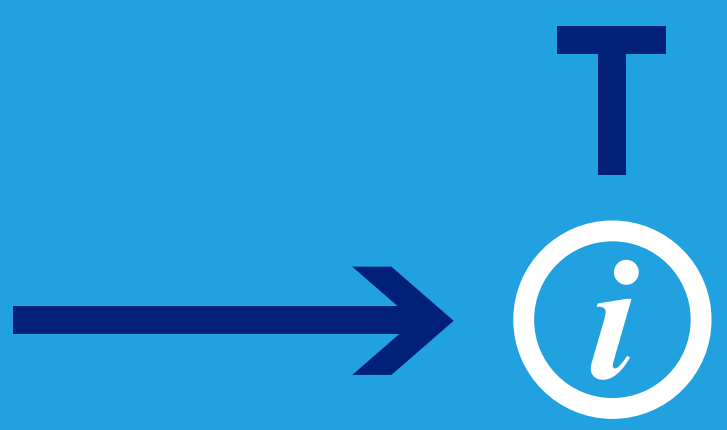

Clear physiological picture
Cardiovascular diseases 
$1 \quad$ INTRODUCTION

\section{LUMPED-PARAMETER CVS MODELS}

Passive vessels:

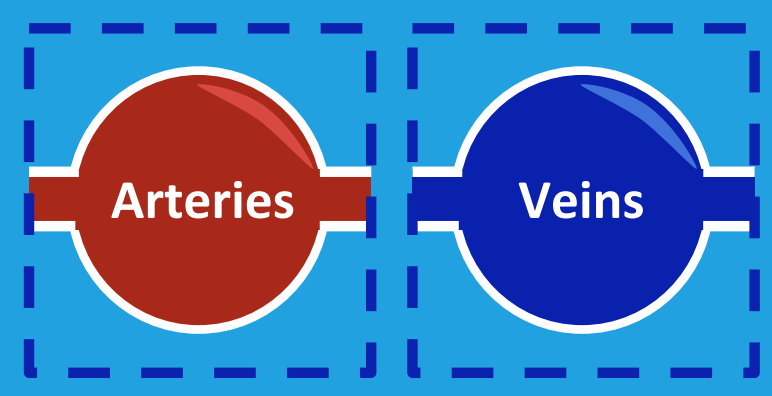

$P=f(V)$

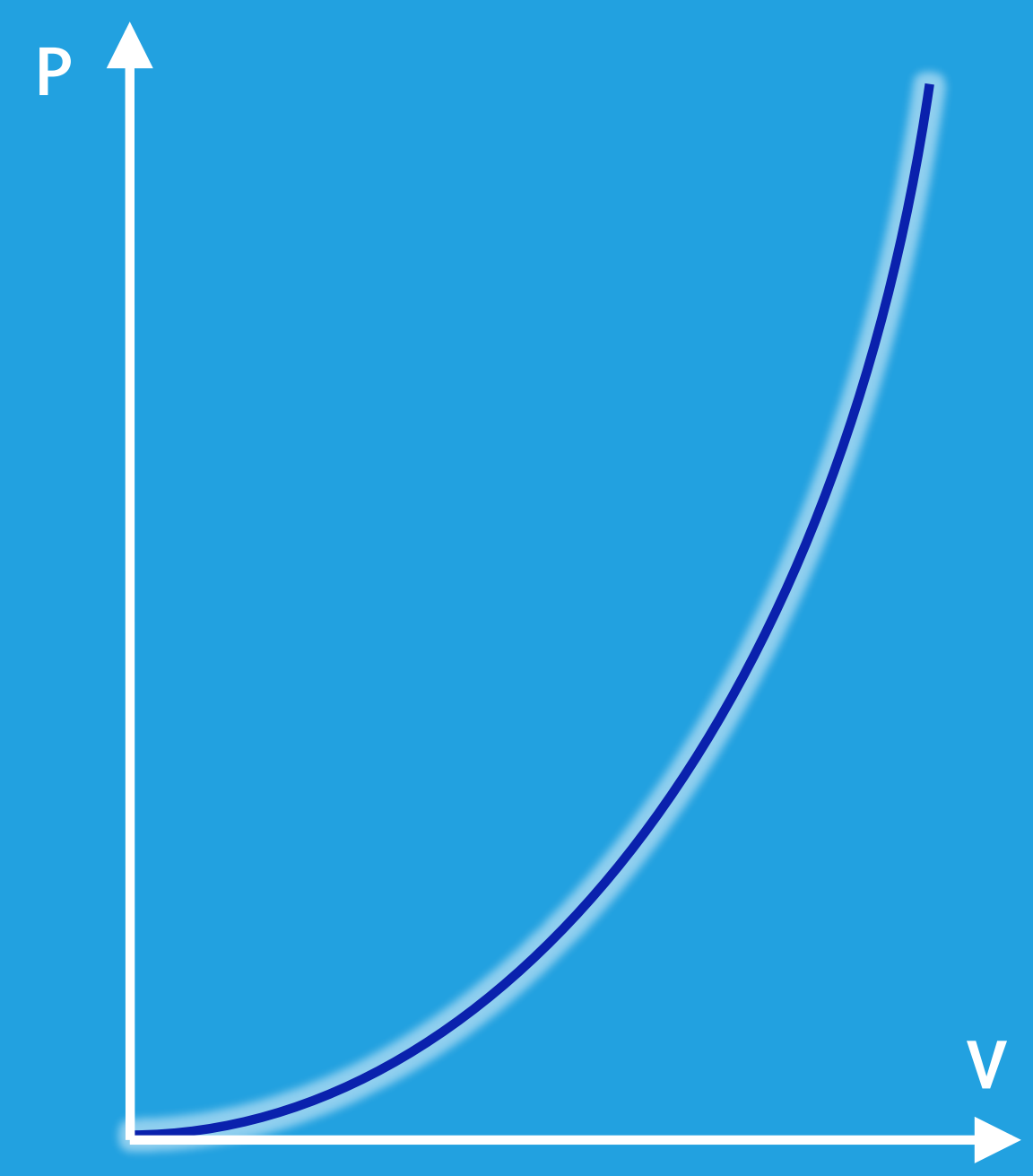


$1 \quad$ INTRODUCTION

\section{LUMPED-PARAMETER CVS MODELS}

Passive vessels:

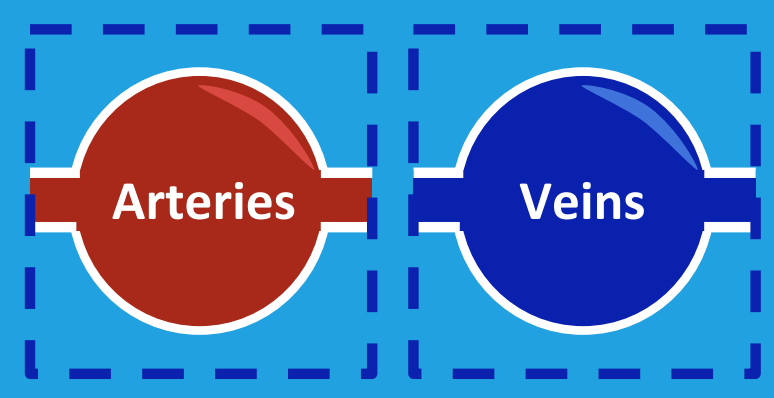

$P=f(V)$

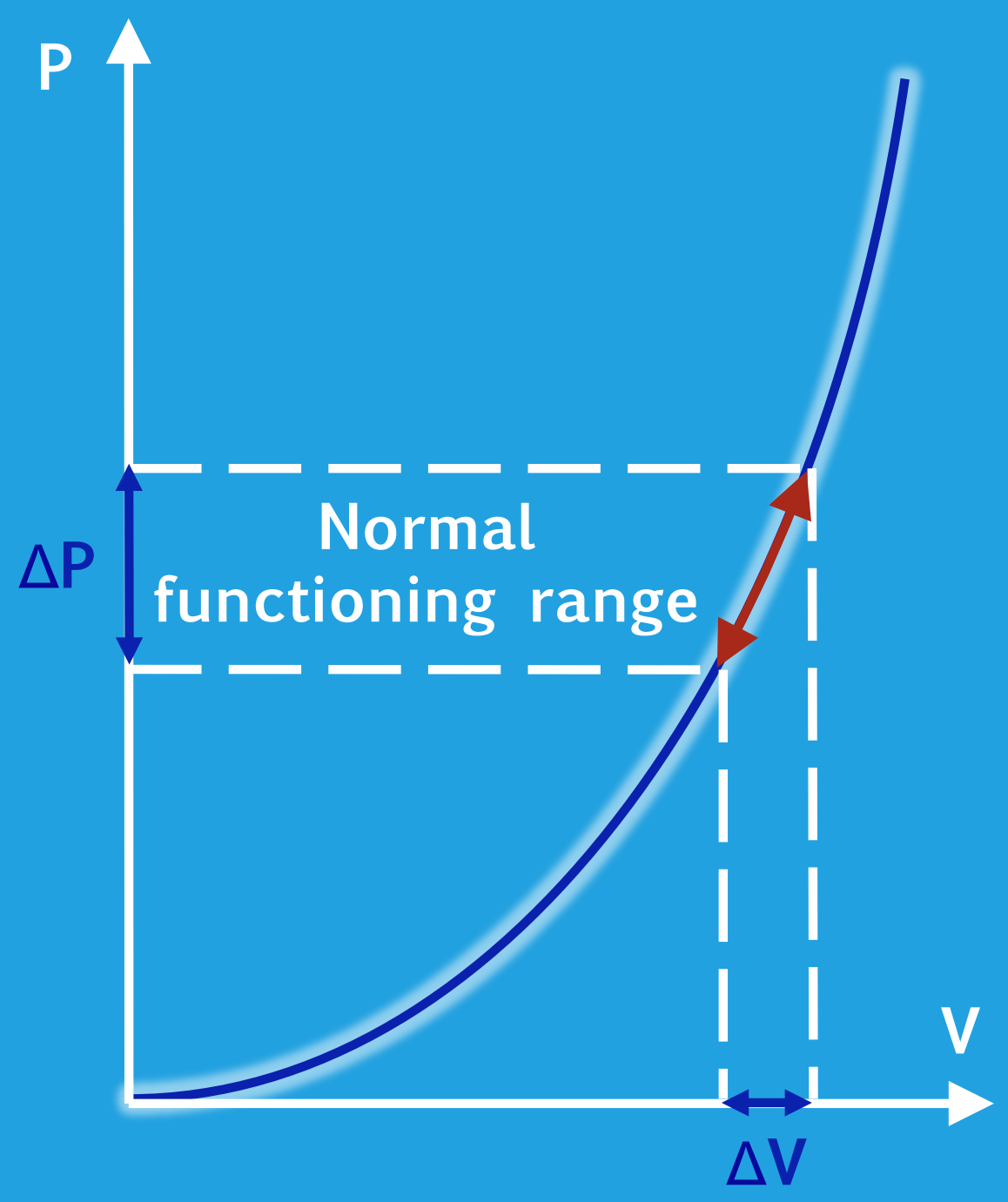


$1 \quad$ INTRODUCTION

\section{LUMPED-PARAMETER CVS MODELS}

Passive vessels:

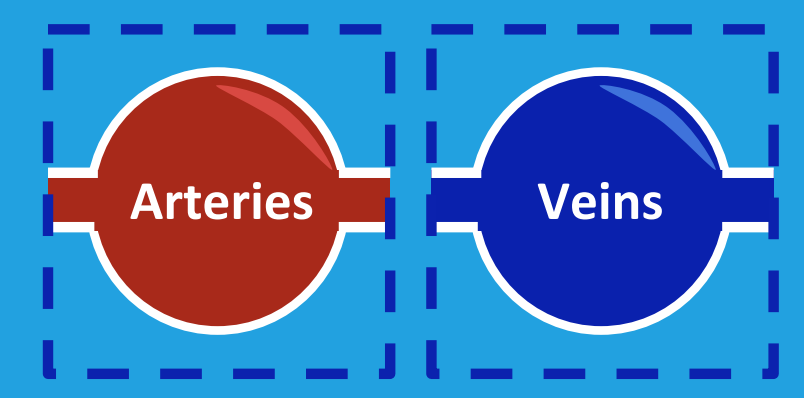

$E=\Delta P / \Delta V$

$P=E\left(V-V_{U}\right)$

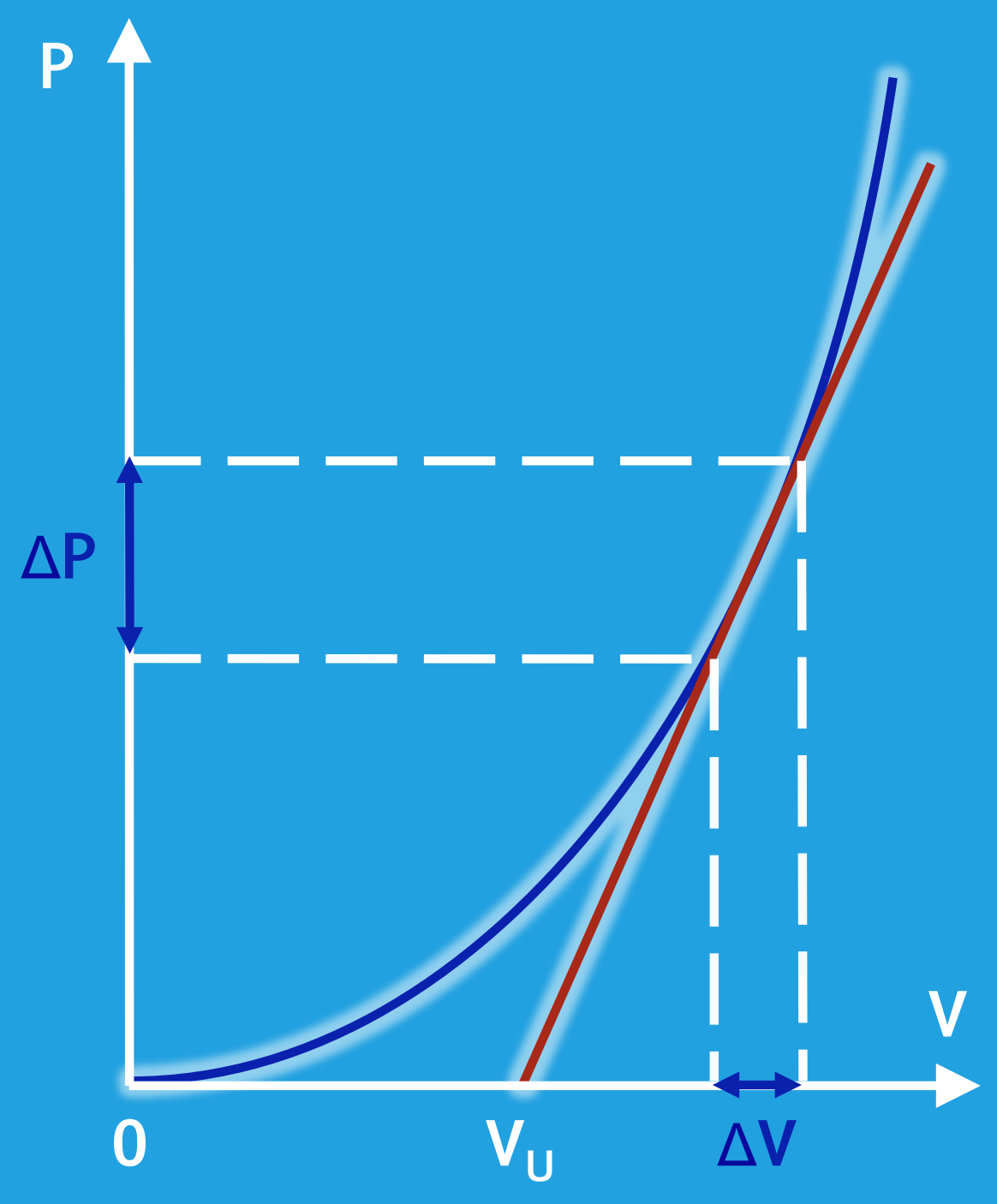


$1 \quad$ INTRODUCTION

\section{LUMPED-PARAMETER CVS MODELS}

Passive vessels:

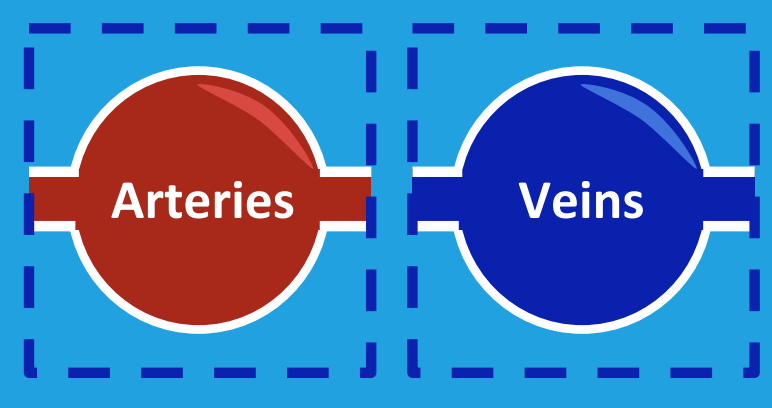

$\mathrm{V}_{\mathrm{S}}=\mathrm{V}-\mathrm{V}_{\mathrm{U}}$ $P=E V_{S}$

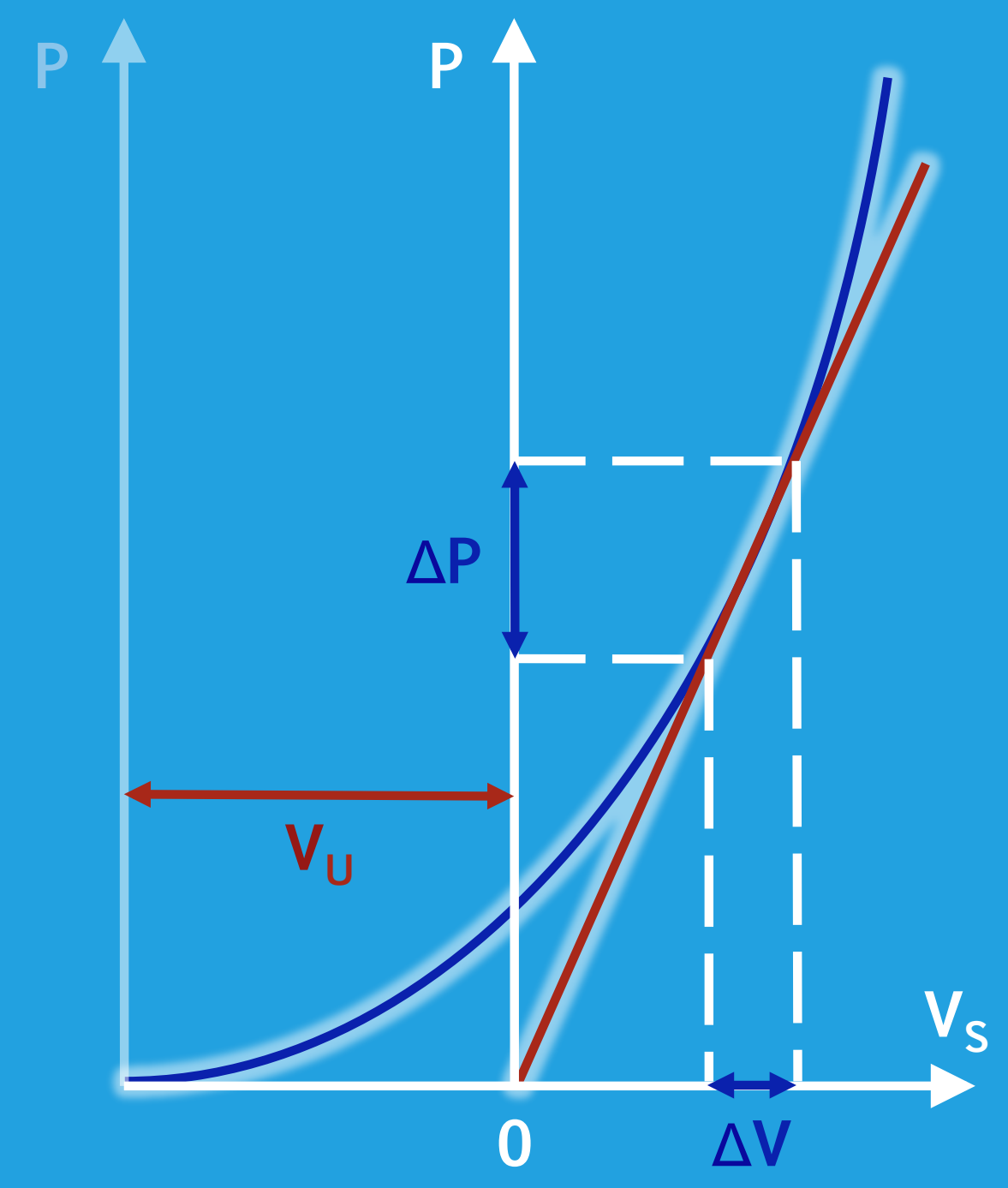


2 TOTAL STRESSED BLOOD VOLUME

V

- Total blood volume:

TBV $=\Sigma_{i} V_{i}$

- Unstressed volumes:

$\mathbf{V}_{\mathrm{U}, \mathrm{i}}$

$$
V_{S}=V-V_{U}
$$

- Total stressed blood volume: $\mathrm{SBV}=\Sigma_{\mathrm{i}} \mathrm{V}_{\mathrm{S}, \mathrm{i}}$ 
$1 \quad$ INTRODUCTION

\section{TOTAL STRESSED BLOOD VOLUME}

- In engineering
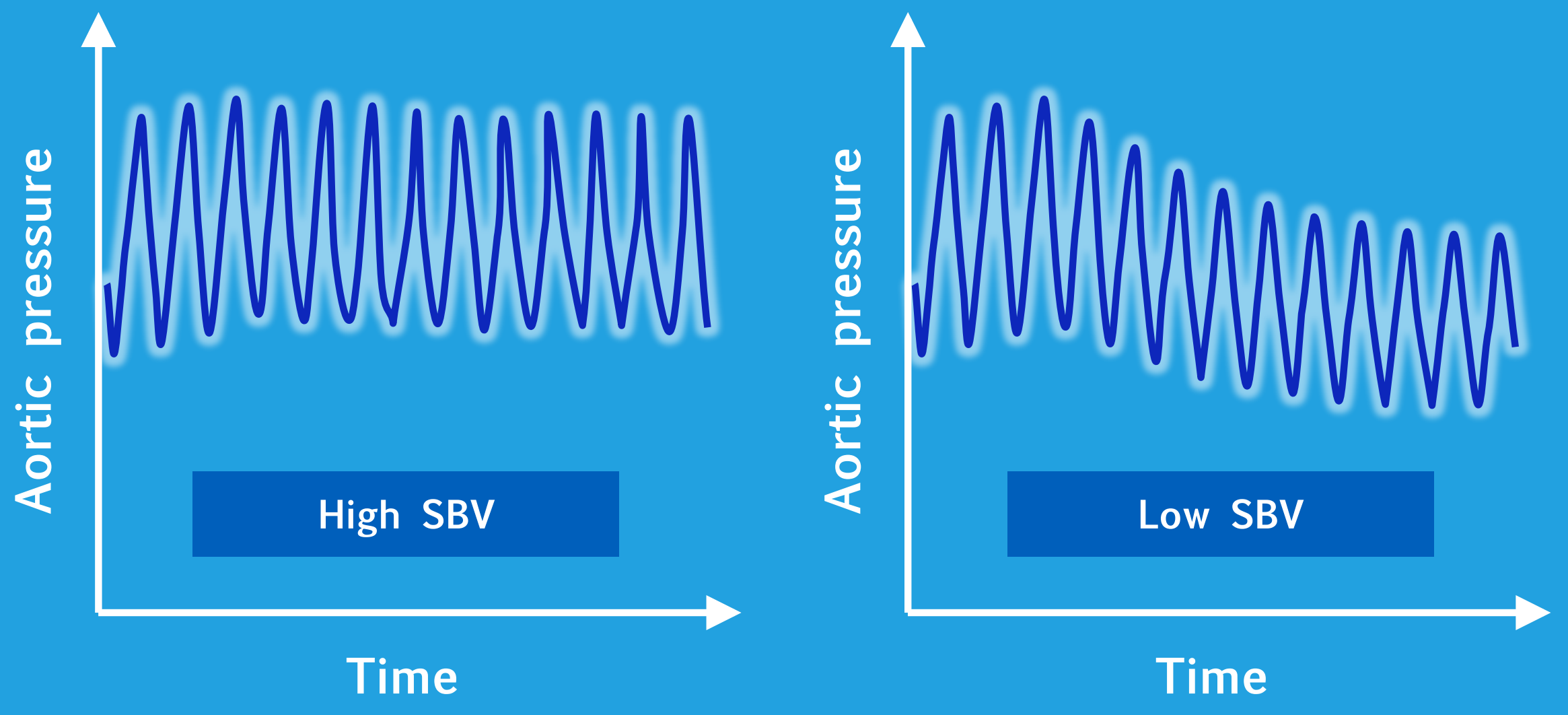
1 INTRODUCTION

\section{TOTAL STRESSED BLOOD VOLUME}

- In medicine (Maas et al., 2012)

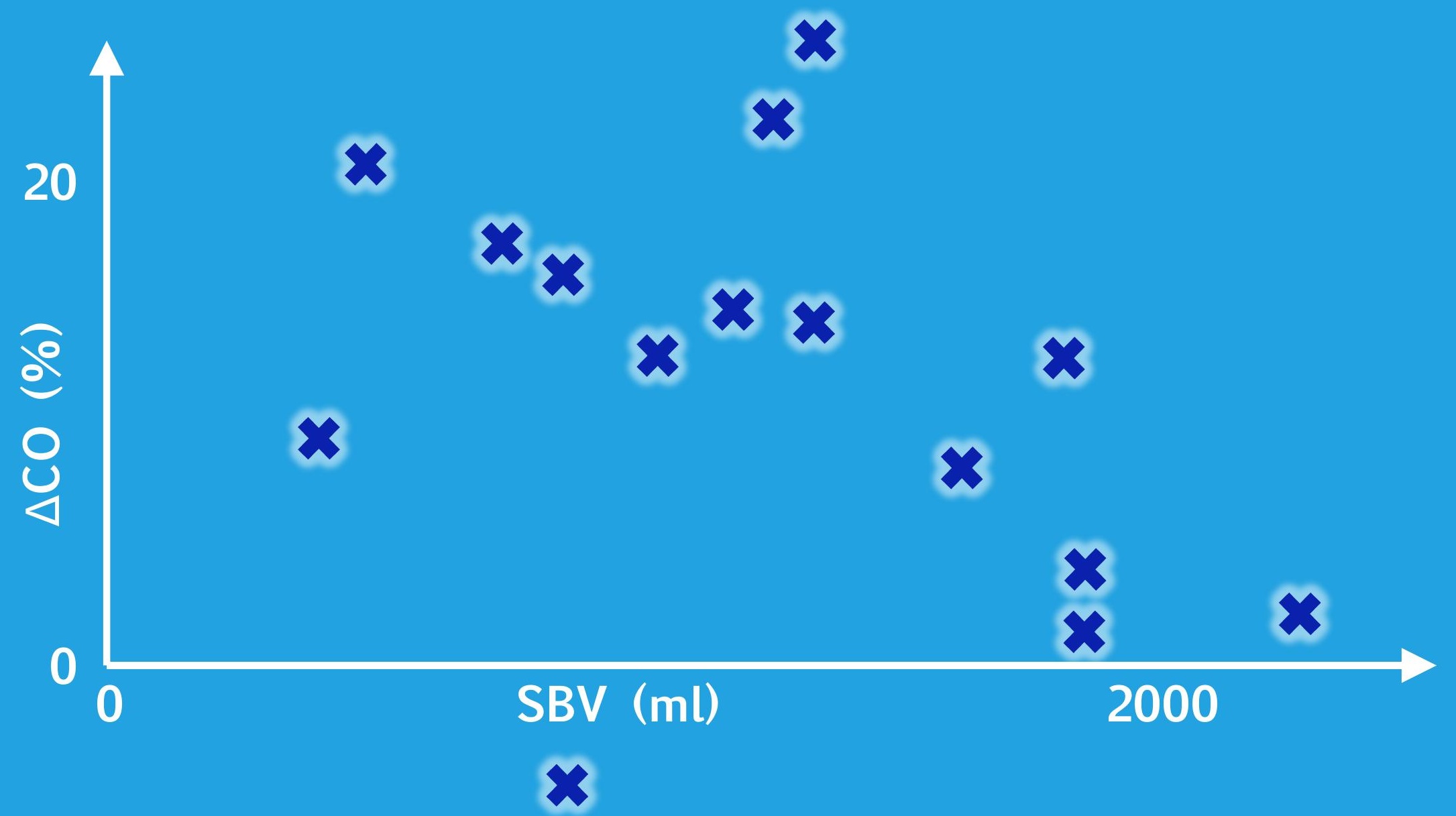




\section{METHODS}

\section{CVS MODEL}

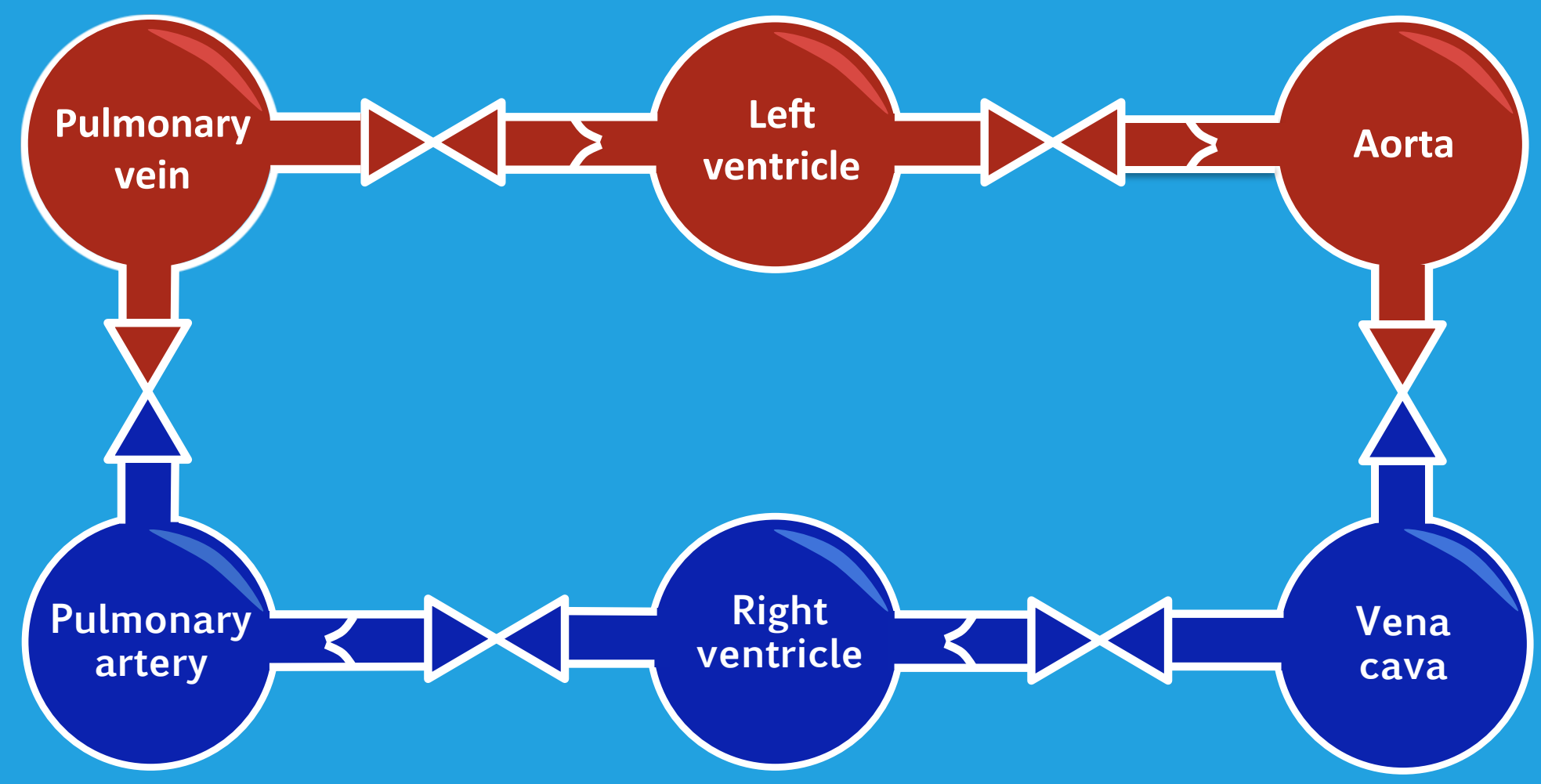

Flow resistance

$>$ Valve 


\section{2

Passive chambers:
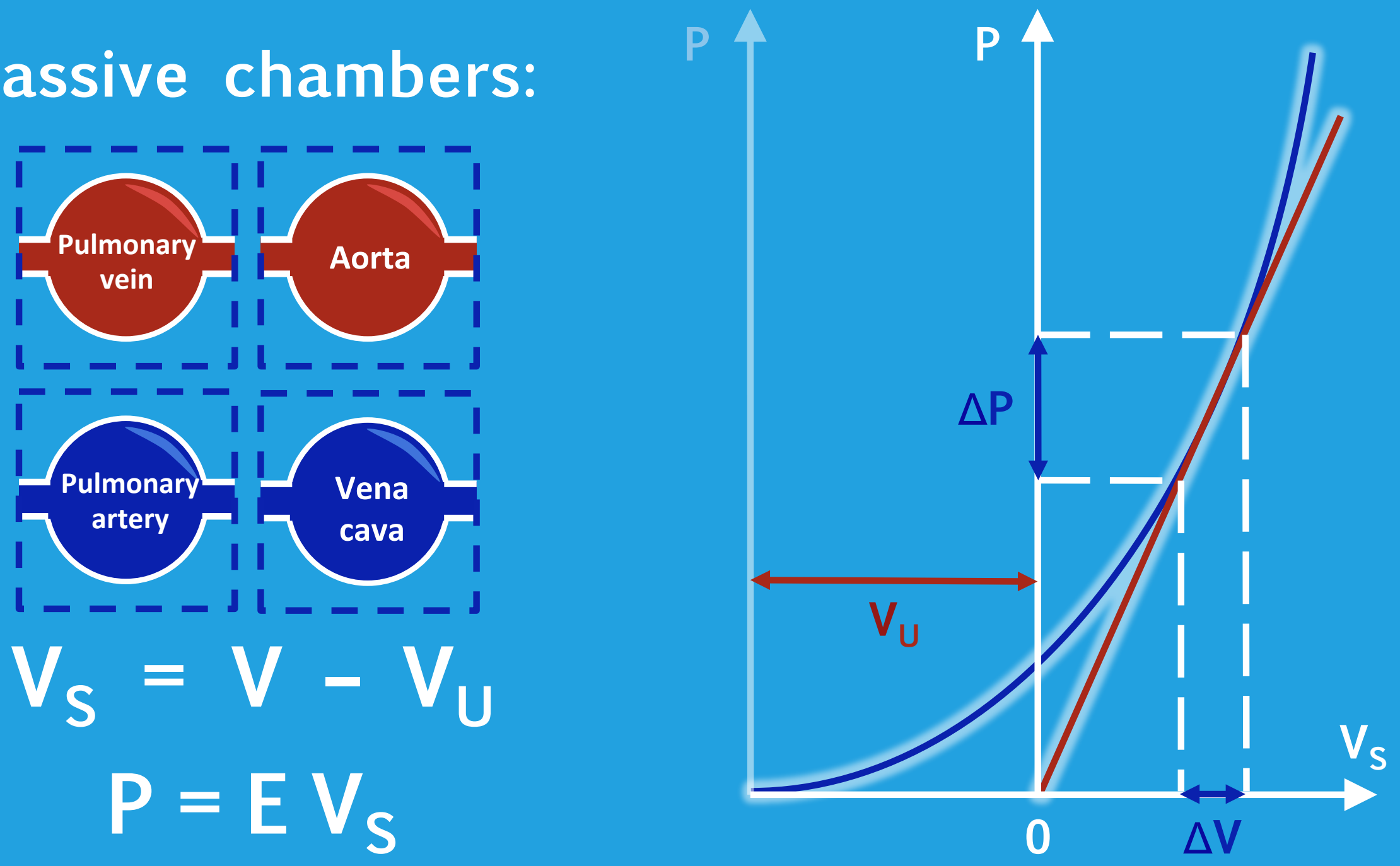


\section{METHODS}

\section{CVS MODEL}

Cardiac chambers:

$P=E e(t) V_{S}$
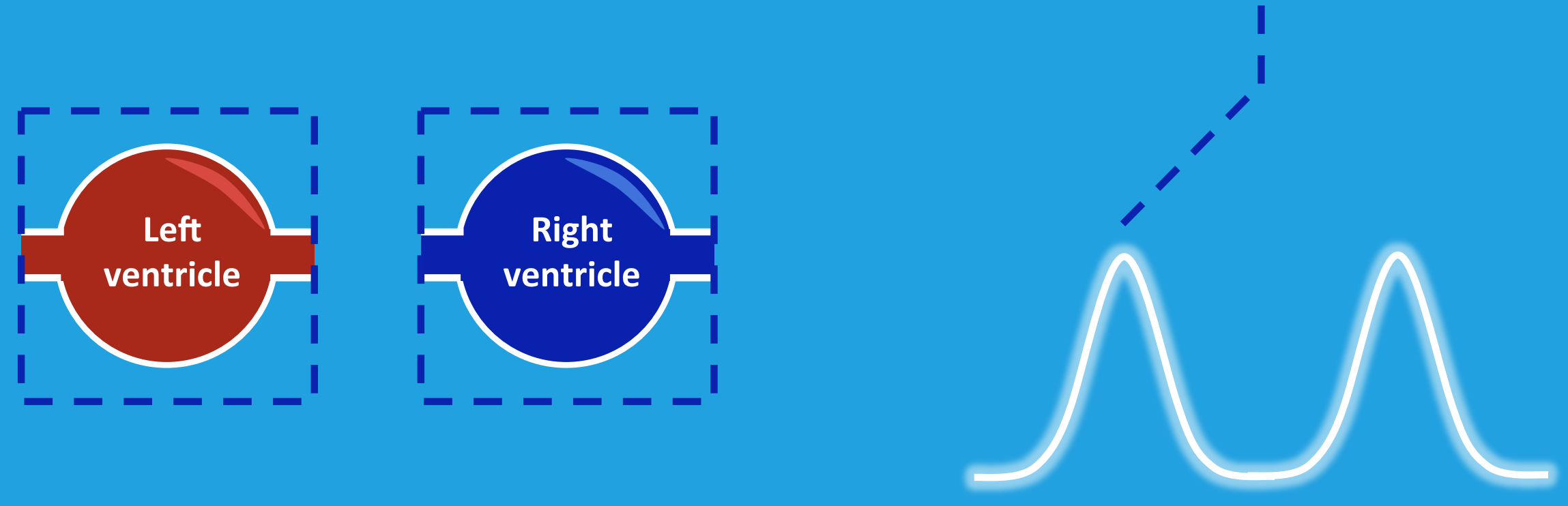

Driver function $e(t)$ in $[0,1]$ 


\section{METHODS}

\section{CVS MODEL}

No valve:

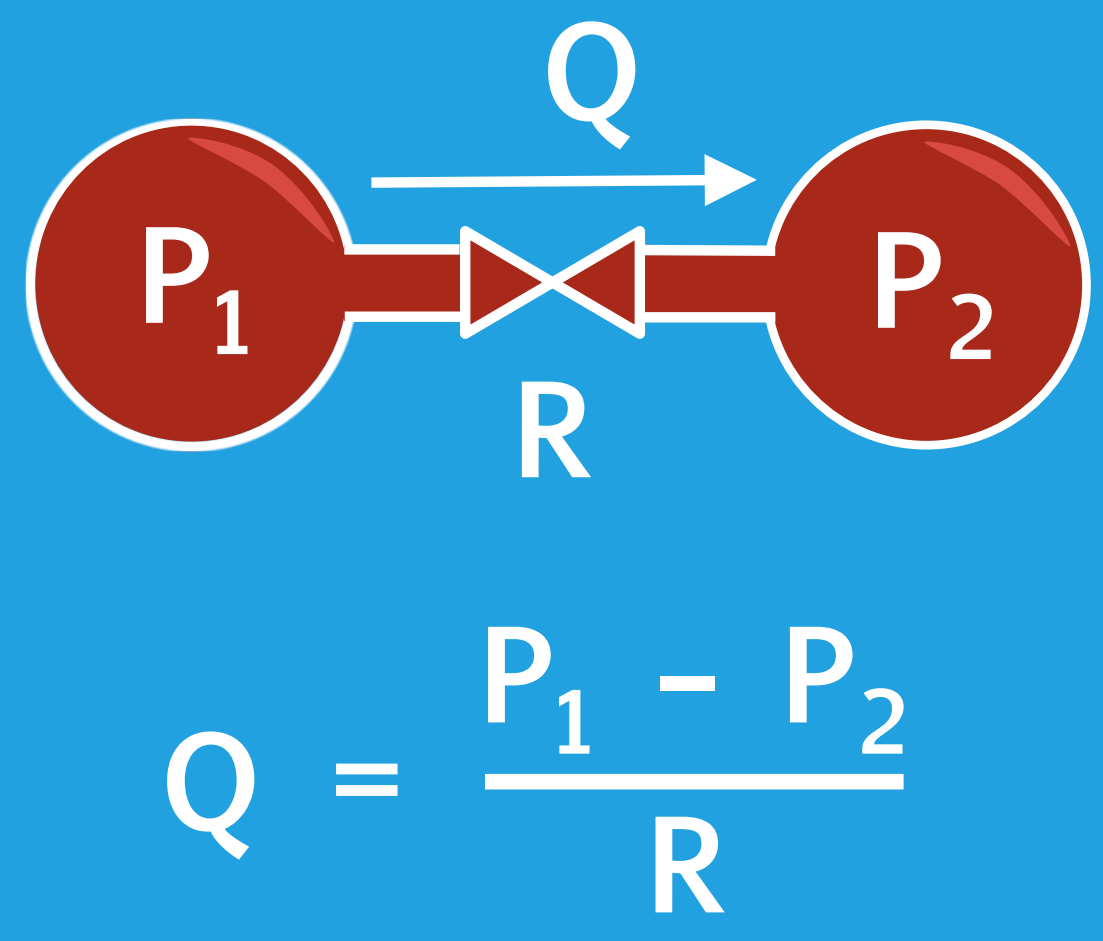

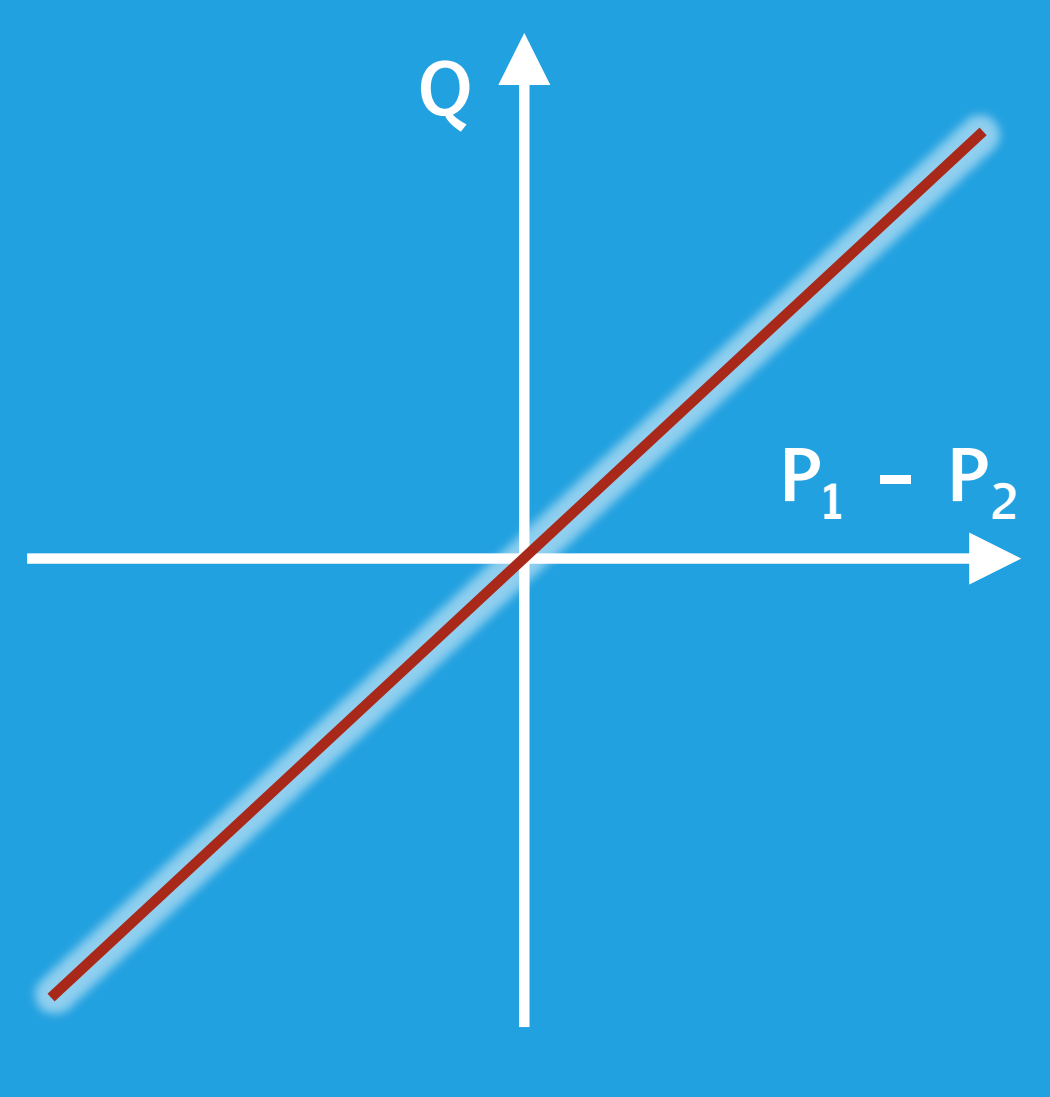




\section{METHODS}

\section{CVS MODEL}

Valve:

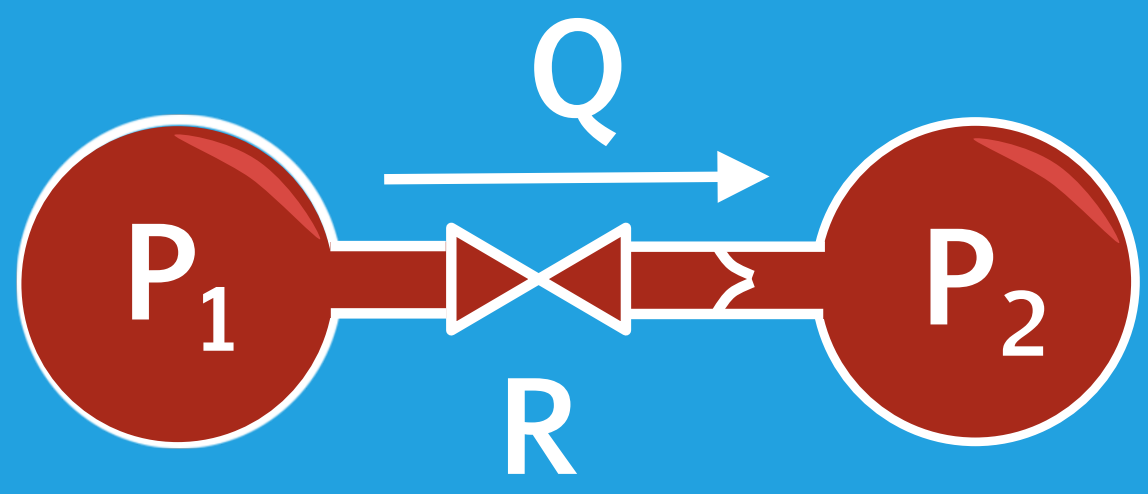

$$
Q=\left\{\begin{array}{cc}
\frac{P_{1}-P_{2}}{R} & \text { if } P_{1}>P_{2} \\
0 & \text { otherwise }
\end{array}\right.
$$

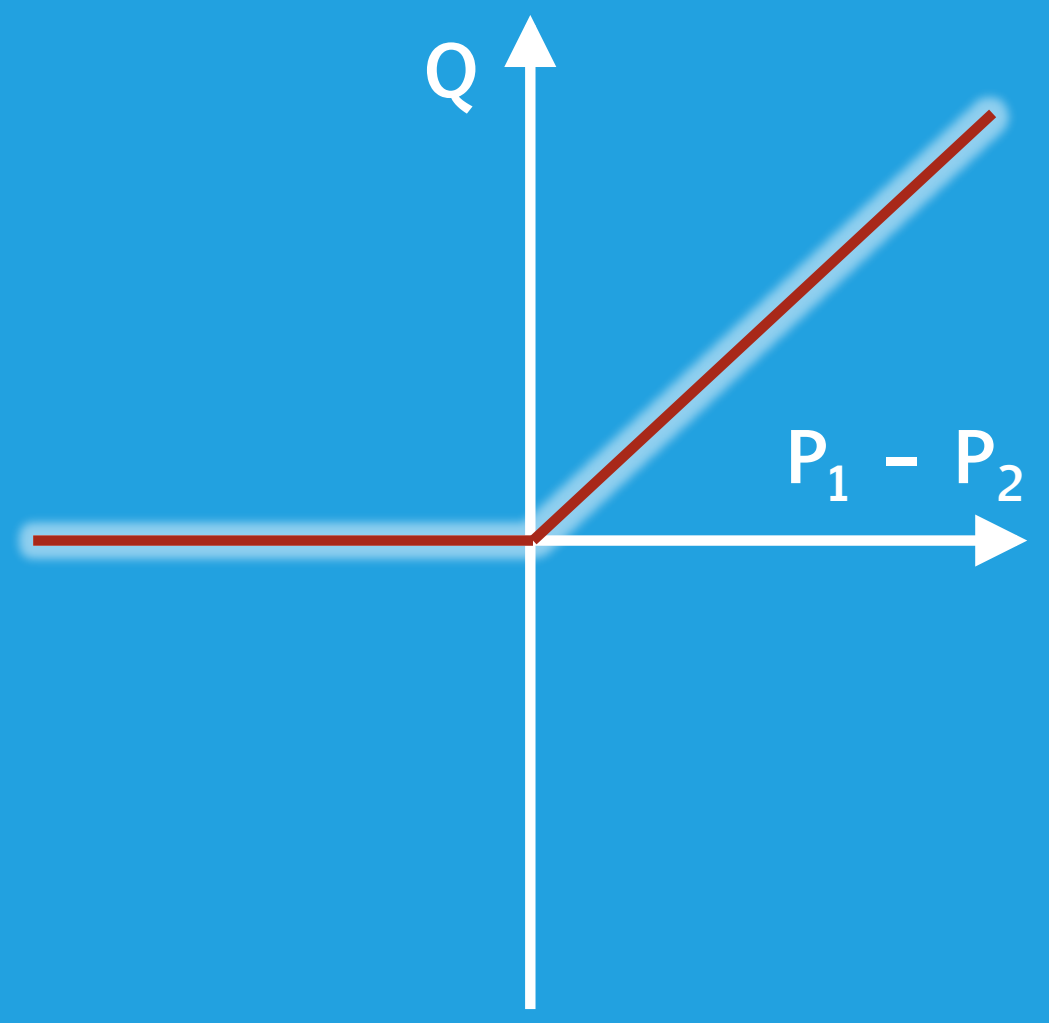


2 METHODS

\section{CVS MODEL}

\section{Continuity equation:}

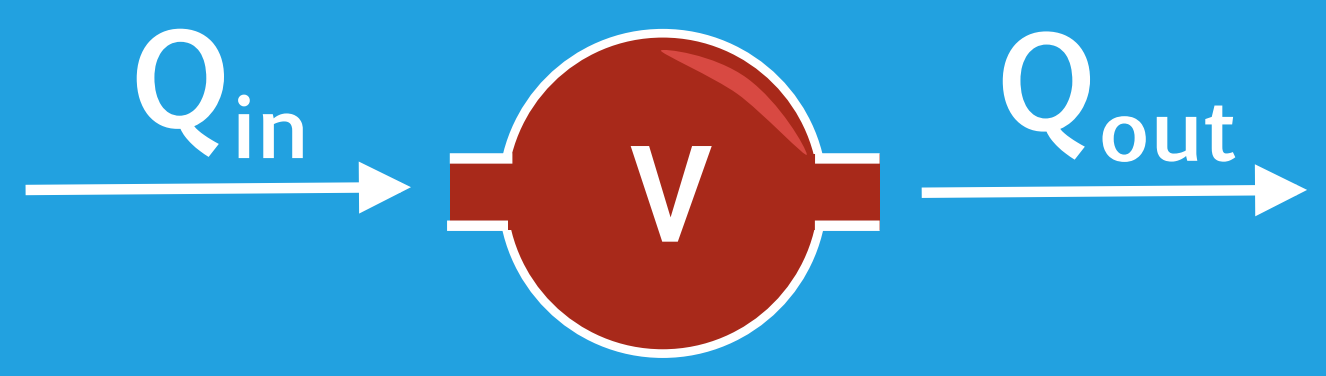

$$
\dot{\mathrm{V}}_{\mathrm{S}}=\mathrm{Q}_{\text {in }}-\mathrm{Q}_{\text {out }}
$$




\section{2 \\ METHODS}

\section{EXPERIMENTAL DATA}

Pig data:

- Aortic and pulmonary artery pressures

- Ventricular pressures

- Ventricular volumes

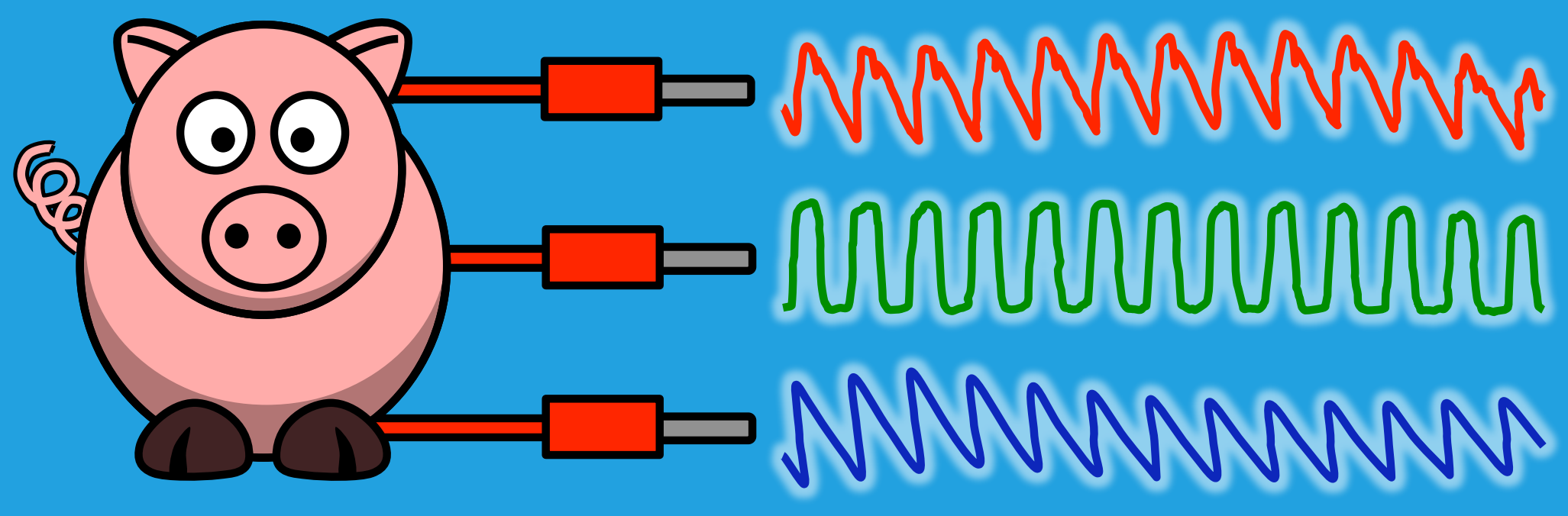


2 METHODS

\section{EXPERIMENTAL DATA}

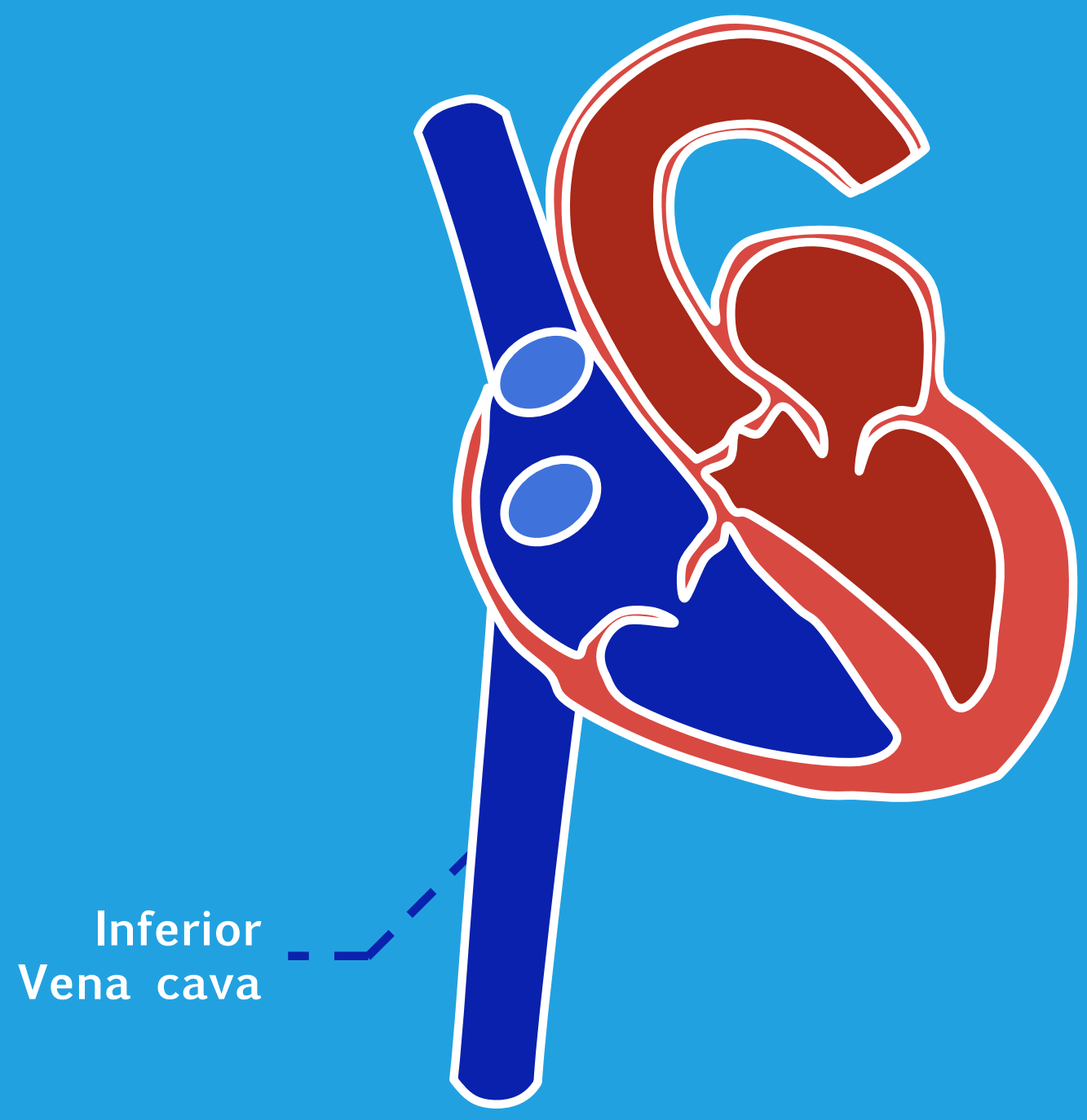


2 METHODS

\section{EXPERIMENTAL DATA}

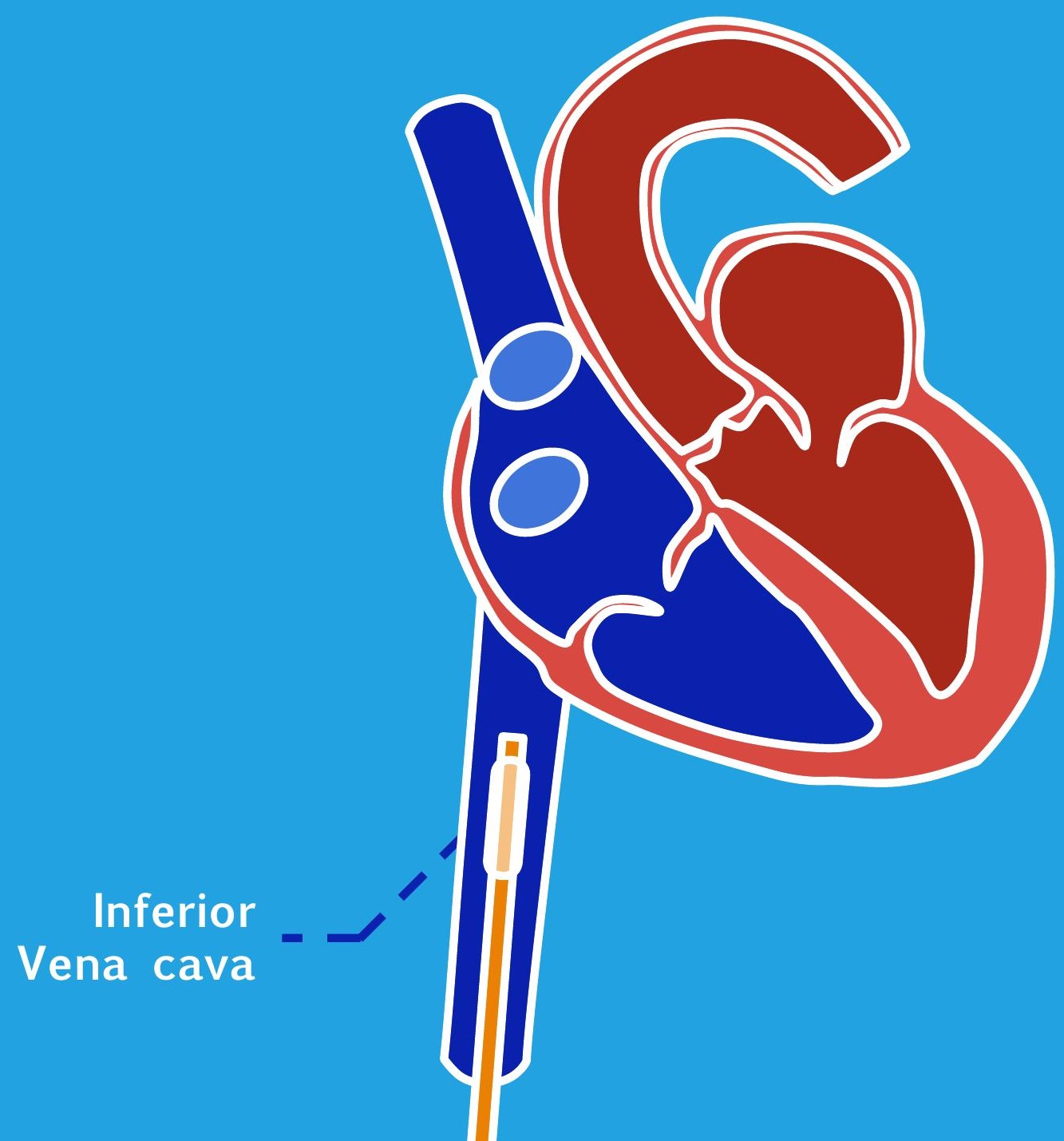


2 METHODS

\section{EXPERIMENTAL DATA}

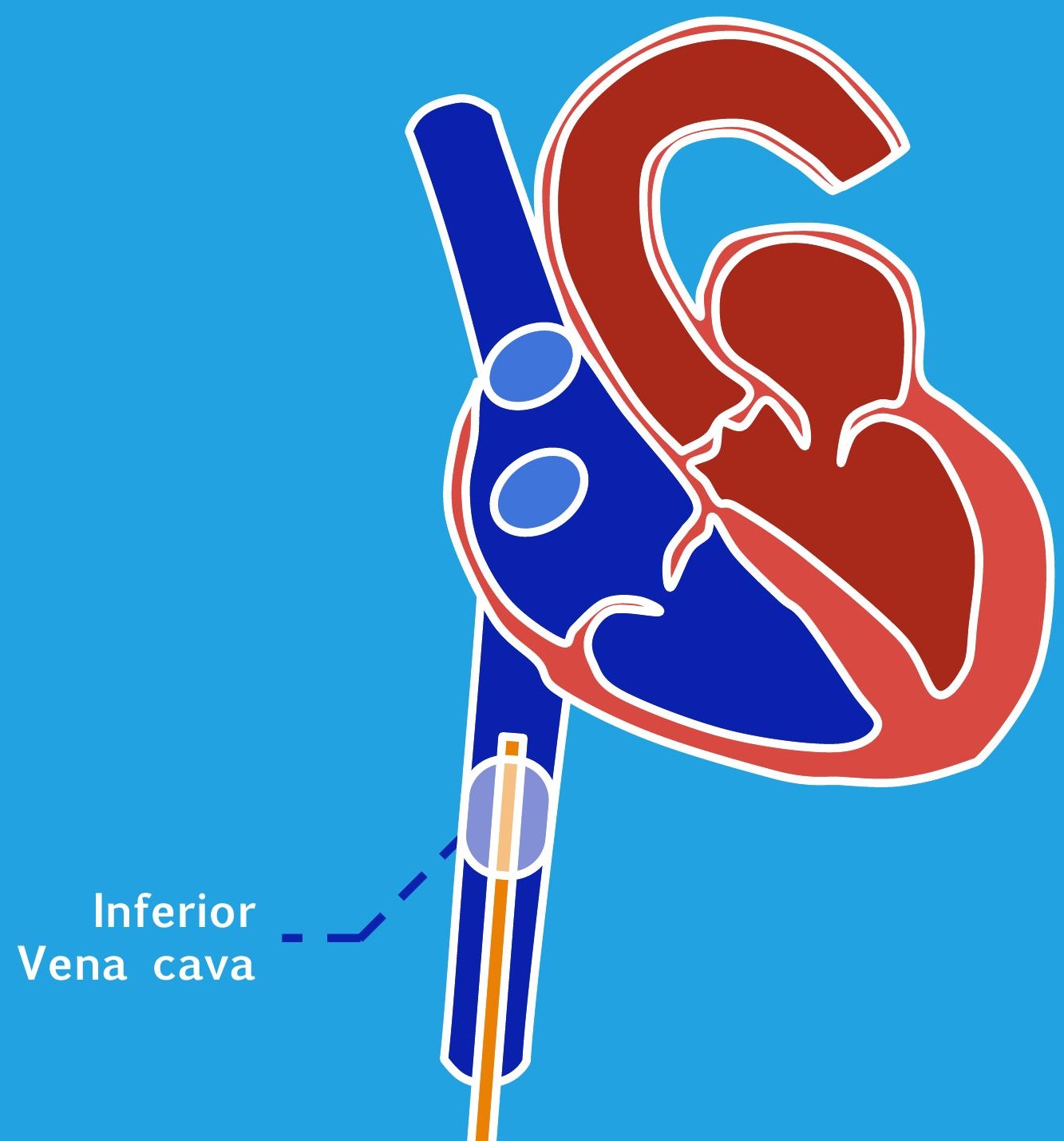




\section{METHODS}

\section{PARAMETER IDENTIFICATION}

Nominal parameter values

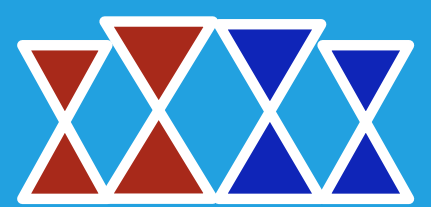

Subset selection algorithm

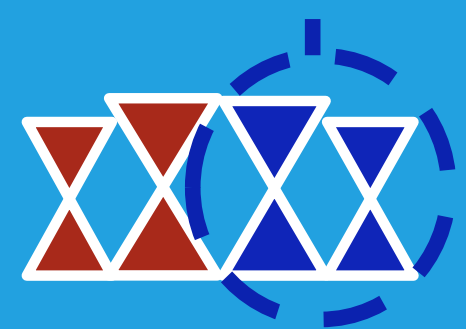

Identification of selected parameters

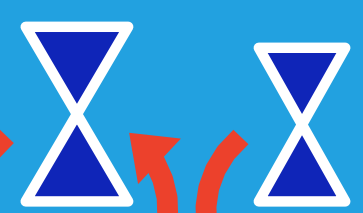




\section{METHODS}

\section{PARAMETER IDENTIFICATION: STEP 1}

Nominal parameter

values

- From the literature

Directly from data, e.g.:

$$
\mathrm{SVR}=\frac{\mathrm{MAP}}{\mathrm{CO}}
$$




\section{2

Nominal parameter values
Subset selection algorithm

- $\mathrm{e}=$ simulations - measurements

- Jacobian matrix $J=\partial e / \partial p$

- Hessian matrix $\mathrm{H} \approx \mathrm{J}^{\top} \mathrm{J}$

- Compute the eigenvalues of $\mathrm{H}$ 


\section{2

Nominal parameter values
Subset selection algorithm

- Select the $r$ largest eigenvalues of $H$

- Find the corresponding parameters through a QR decomposition

- Select these $r$ parameters for optimization 


\section{2

\section{PARAMETER IDENTIFICATION: STEP 3}

\section{Nominal parameter values}

Subset selection algorithm
Identification of selected parameters

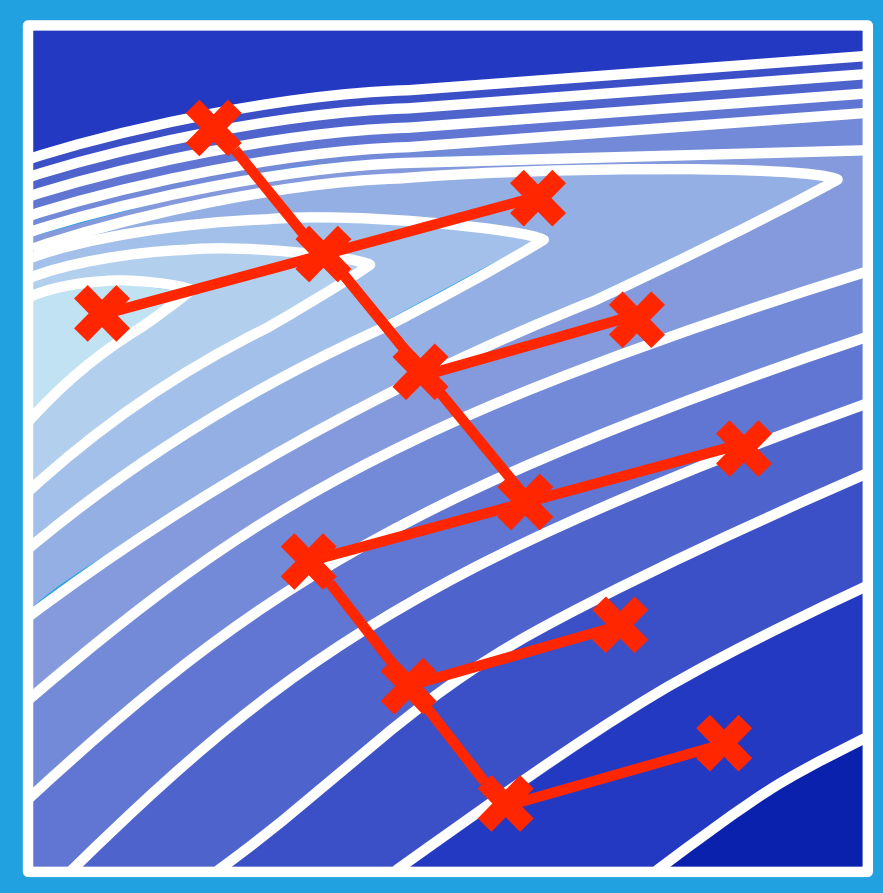

\section{Using the direct search method and the initial values computed at step 1 .}




\section{$3 \quad$ RESULTS}

\section{NUMBER OF PARAMETER SELECTIONS}

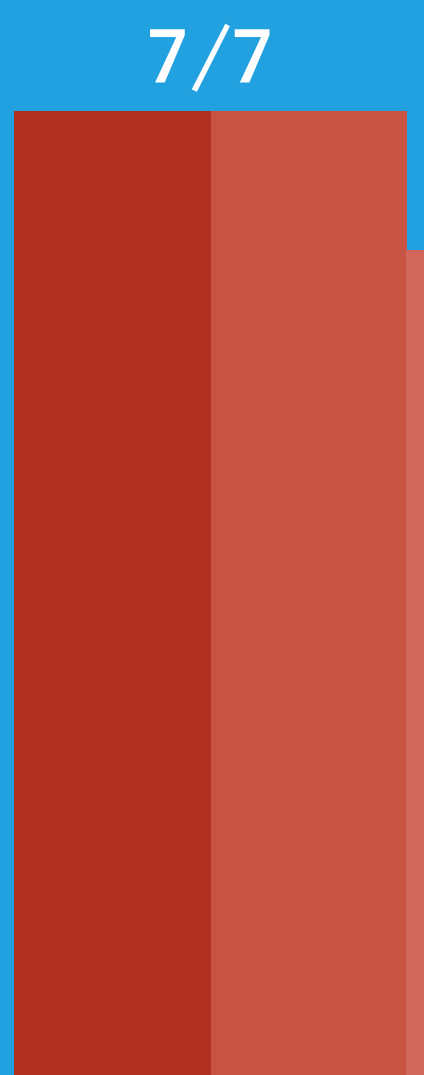

$6 / 7$

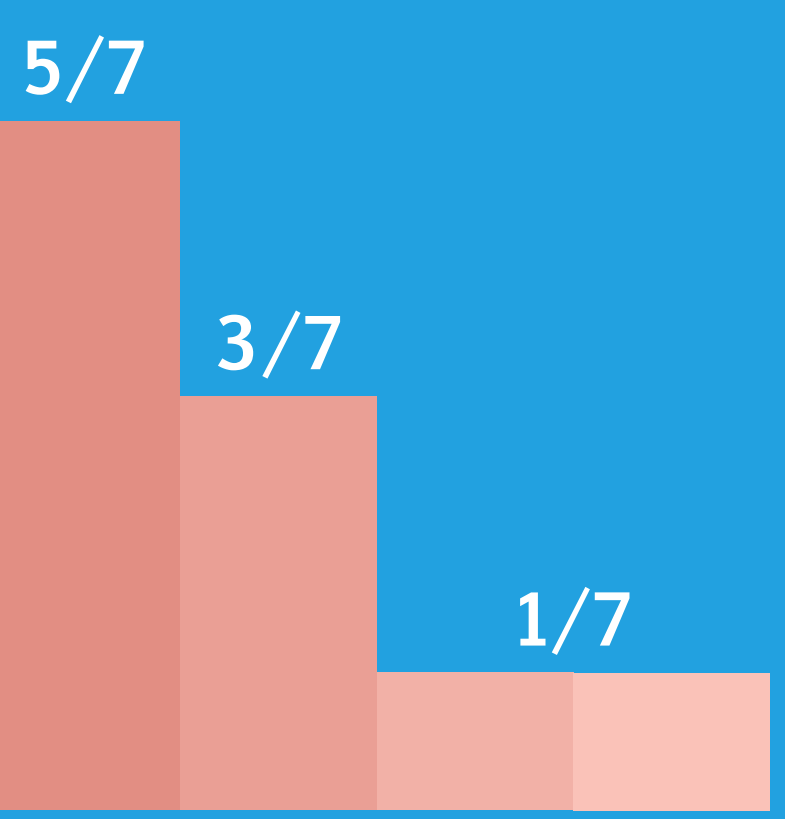

$0 / 7$

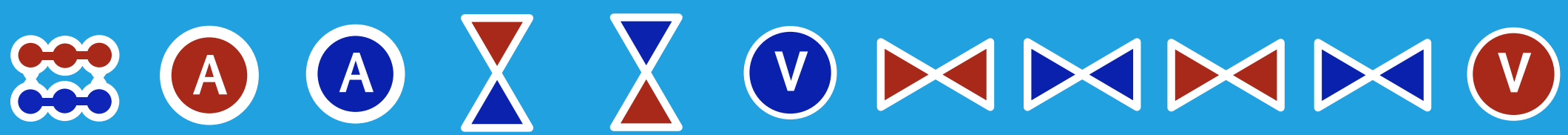
SBV AE PAE PVR SVR VCE MVR TVR AVR PVR PVE 


\section{RESULTS}

\section{PARAMETER ADJUSTMENT}

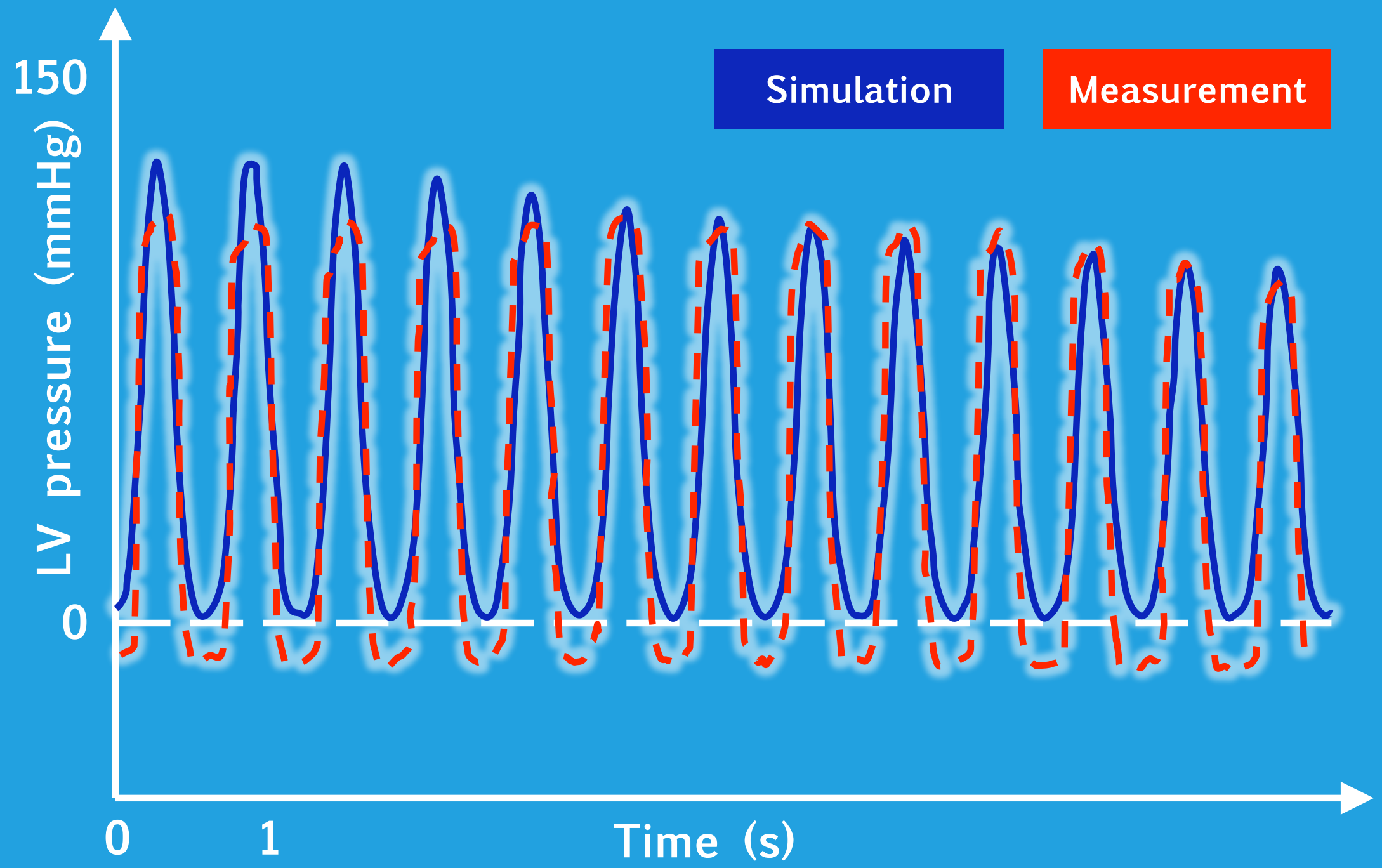




\section{RESULTS}

\section{PARAMETER ADJUSTMENT}

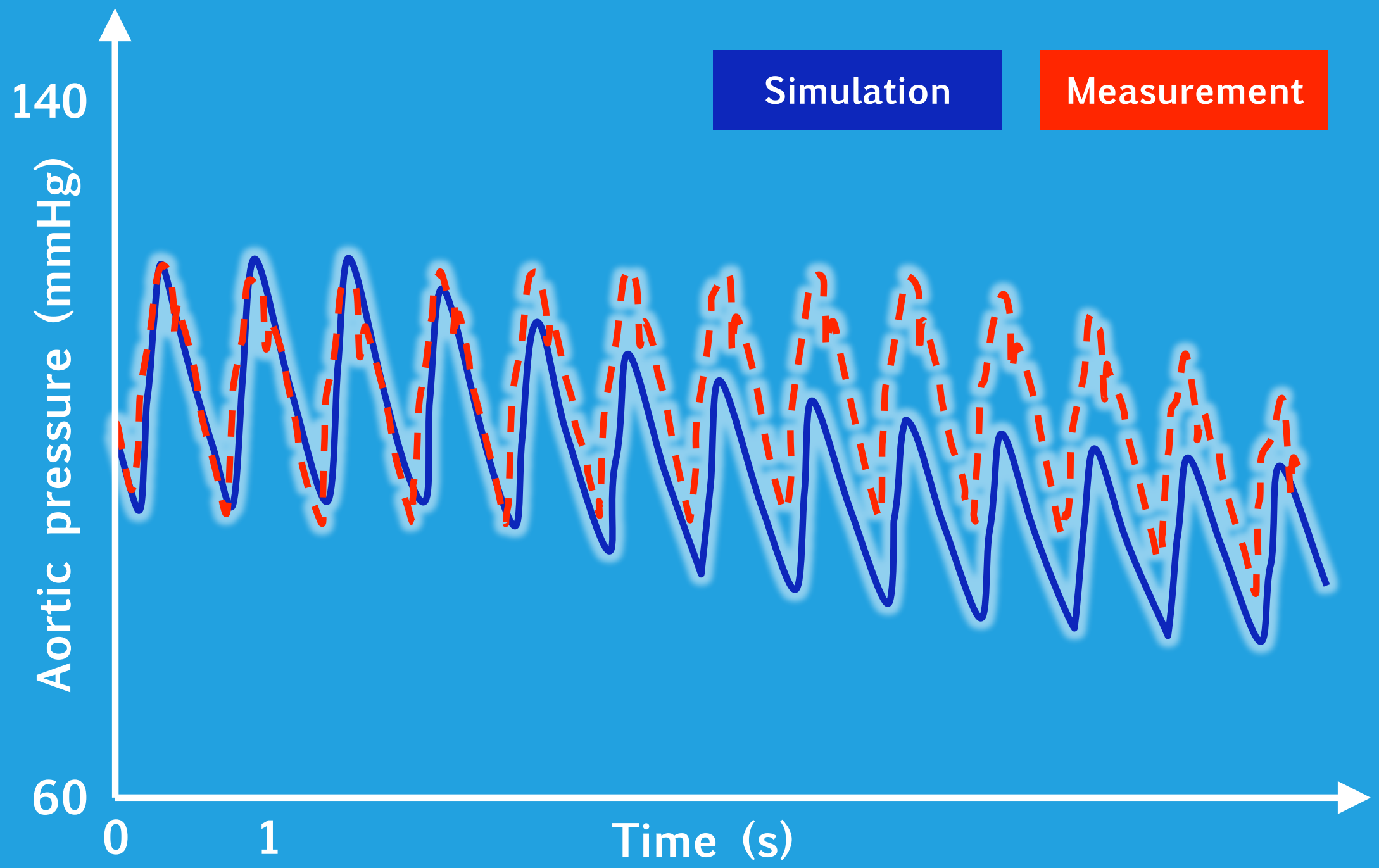




\section{RESULTS}

\section{PARAMETER ADJUSTMENT}

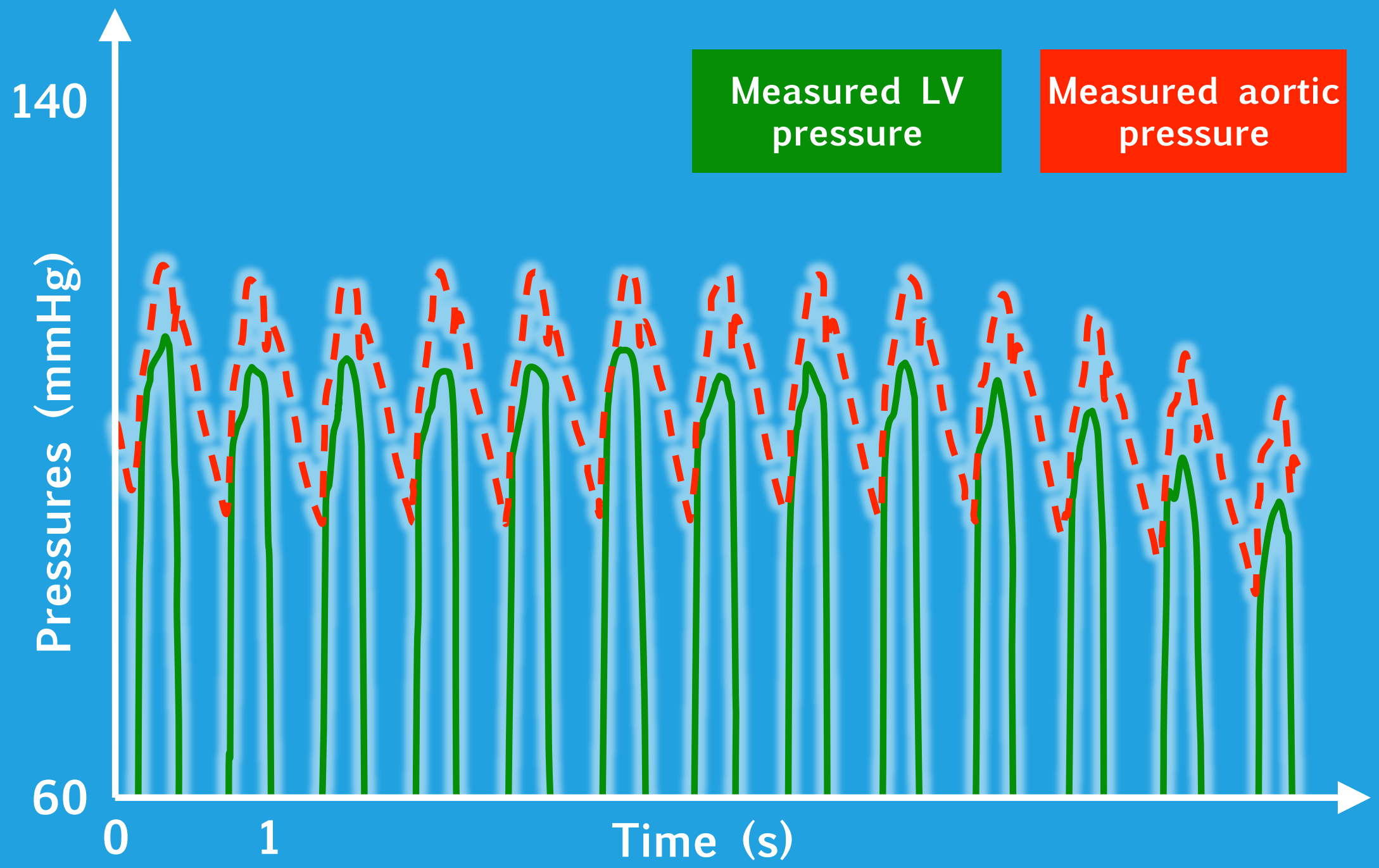


$3 \quad$ RESULTS

\section{VALUE OF SBV (ml)}

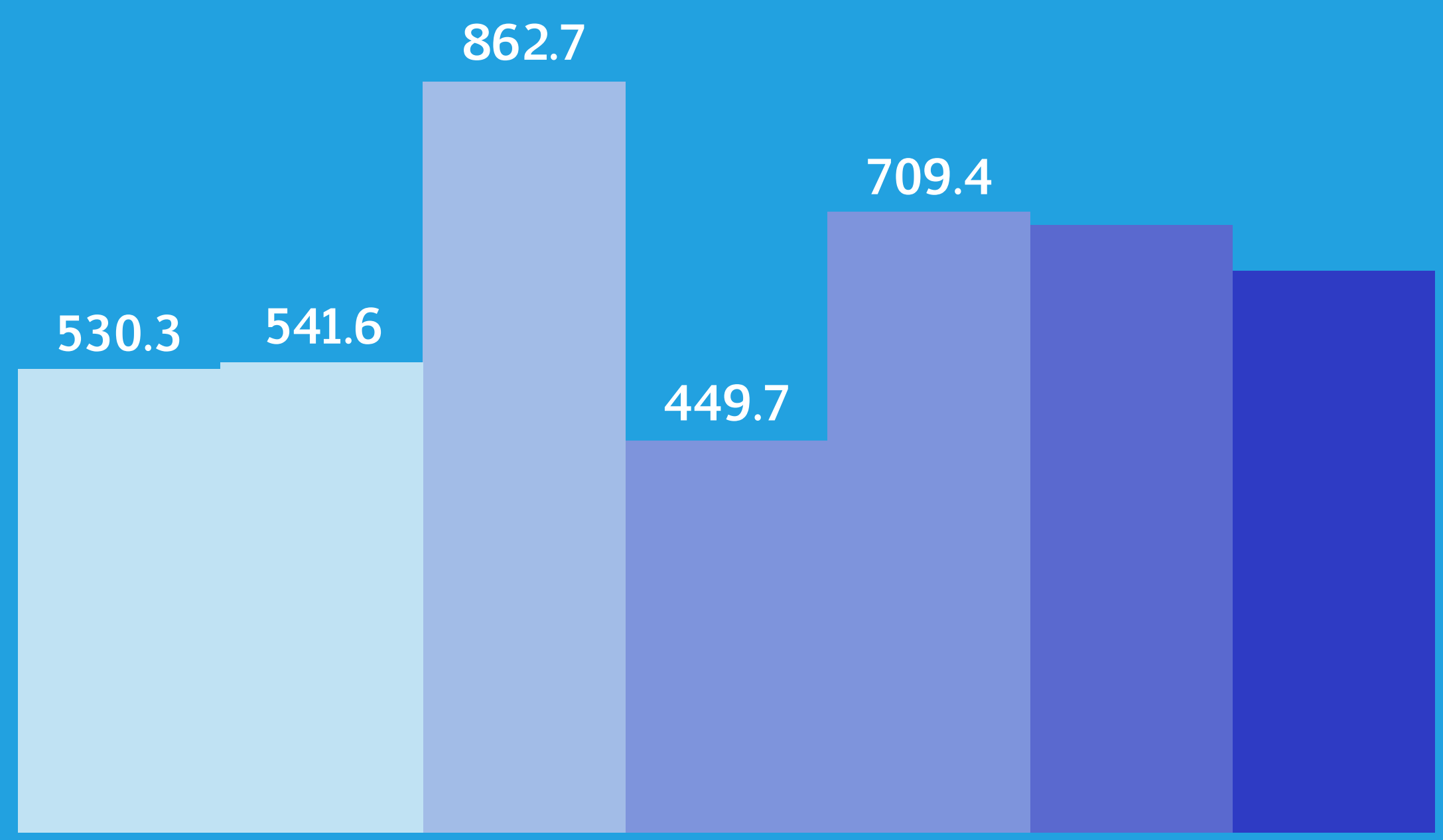

Datasets 


\section{$4 \quad$ LIMITATIONS}

The method needs validation.

- With the usual way to compute SBV.

- Track SBV during vascular filling.

- Using simulated data. 


\section{4

The method needs validation.

- With the usual way to compute SBV.

- Track SBV during vascular filling.

- Using simulated data. 


\section{4

The method needs validation.

- With the usual way to compute SBV.

- Track SBV during vascular filling.

- Using simulated data. 
The method needs validation.

- With the usual way to compute SBV.

- Track SBV during vascular filling.

- Using simulated data. 


\section{5

The method could be made fully non-invasive:

- SBV is an important parameter.

No need for ventricular pressures.

- Change load by raising the legs.

No need for vena cava occlusion. 
The method could be made fully non-invasive:

- SBV is an important parameter.

No need for ventricular pressures.

- Change load by raising the legs.

No need for vena cava occlusion. 
The method could be made fully non-invasive:

- SBV is an important parameter.

No need for ventricular pressures.

- Change load by raising the legs.

No need for vena cava occlusion. 
- Model-based method to compute SBV from preload reduction data.

- SBV is an important parameter

If validated, the method could provide a non-invasive way to track SBV. 
- Model-based method to compute SBV from preload reduction data.

- SBV is an important parameter

\section{If validated, the method could provide a non-invasive way to track SBV.}


- Model-based method to compute SBV from preload reduction data.

- $\mathrm{SBV}$ is an important parameter
If validated, the method could provide a non-invasive way to track SBV. 
Thanks for your attention! Questions? 


\section{METHODS}

\section{EXPERIMENTAL DATA}

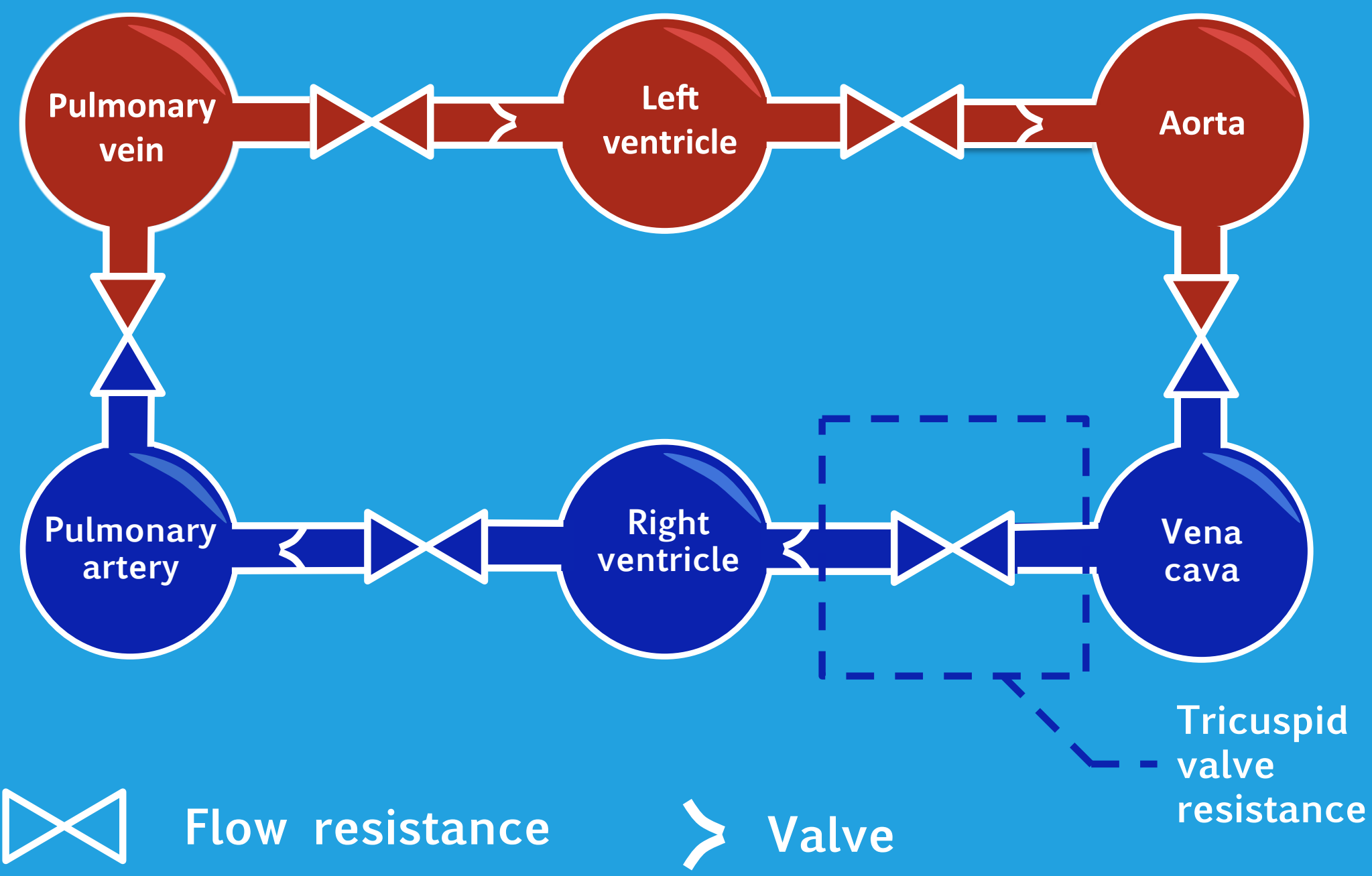




\section{METHODS}

\section{EXPERIMENTAL DATA}

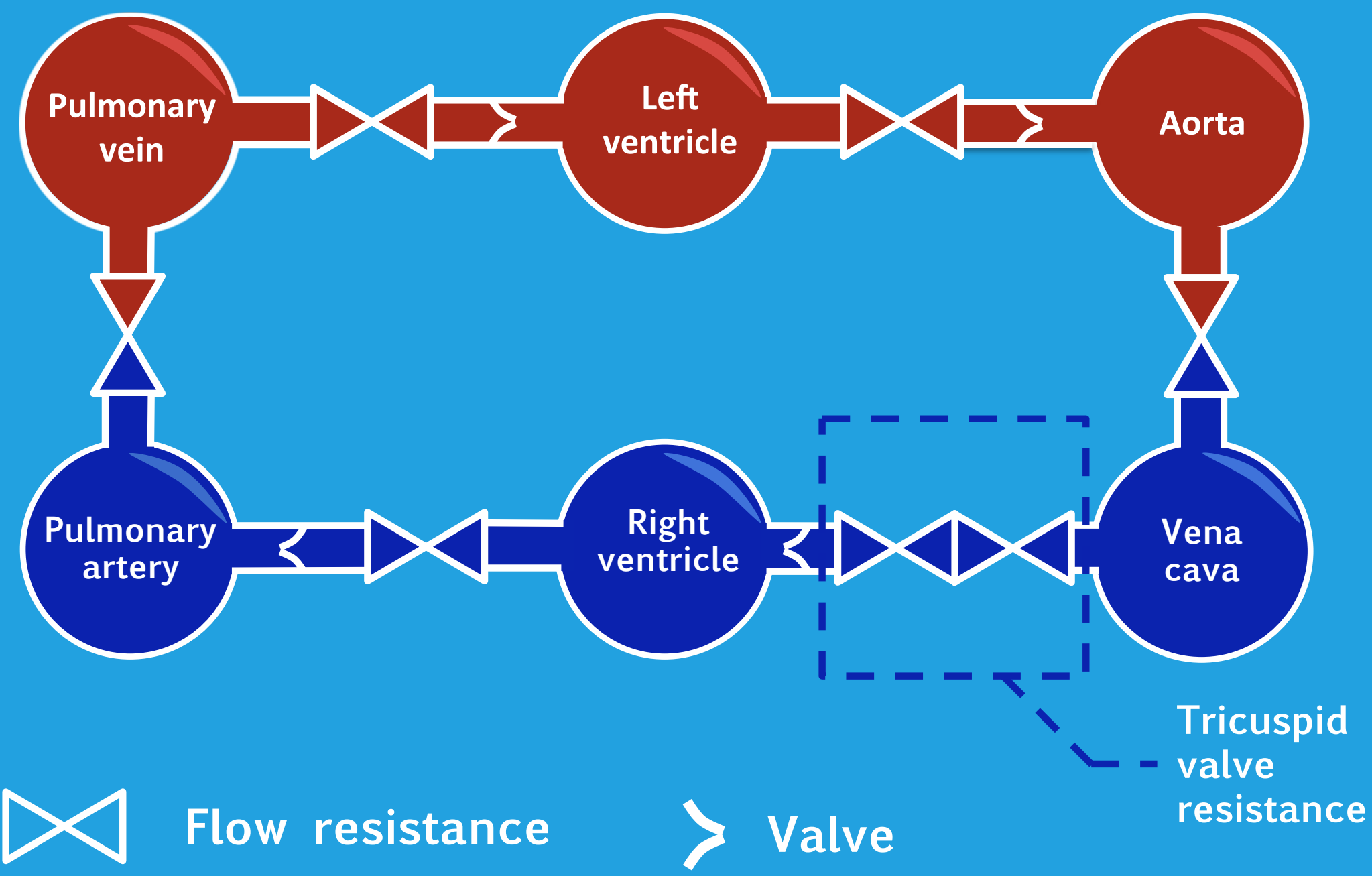


3 RESULTS

\section{SBV VERSUS WEIGHT}

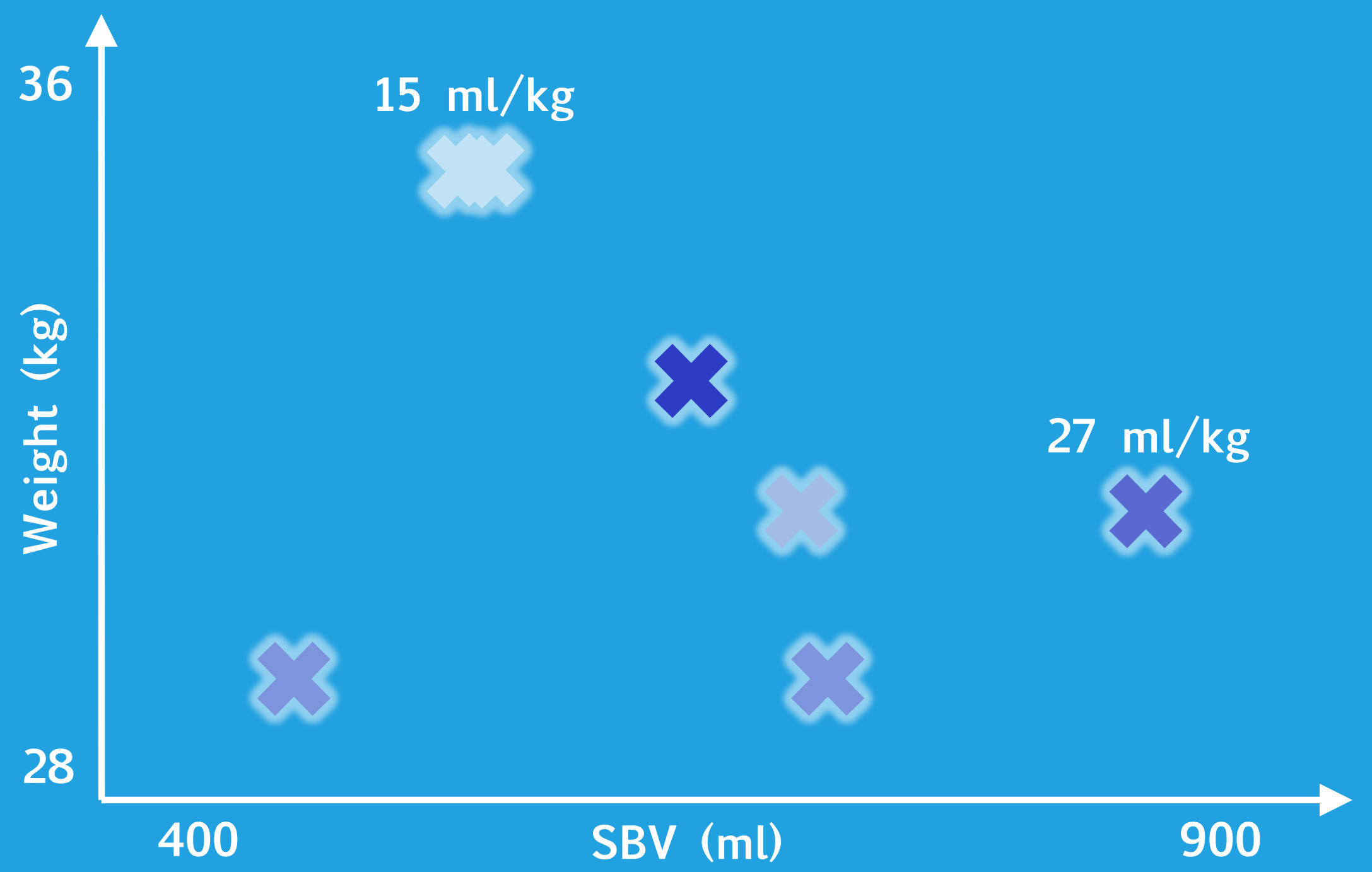

